IRA-International Journal of Technology \& Engineering ISSN 2455-4480

Proceedings of the

International Conference on Science \& Engineering for Sustainable Development (2017)

Pg. no.327-339

Published by: Institute of Research Advances https://research-advances.org/index.php/IRAJTE

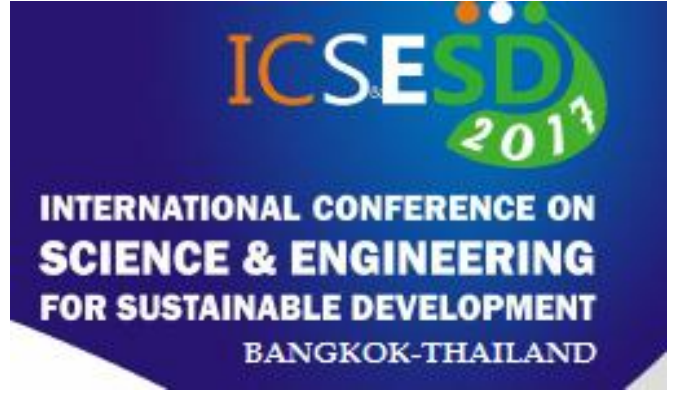

\title{
Community Wastewater Treatment with Attached Growth Assisted Constructed Wetland Reactor
}

\author{
Nitin W. Ingole ${ }^{1}$, Mangesh L. Gulhane ${ }^{2}$ \\ ${ }^{1}$ Professor and Director (R and D) Department of Civil Engineering, Prof. Ram Meghe \\ Institute of Technology and Research, Badnera, Amravati - 444 701, India. \\ ${ }^{2}$ Associate Professor, Department of Civil Engineering, Government College of \\ Engineering, Amravati, India.
}

Type of Review: Originality Check \& Peer Review under the responsibility of the Scientific Committee of the Conference and The Institution of Engineers (India). DOI: http://dx.doi.org/10.21013/jte.ICSESD201731

\section{How to cite this paper:}

Ingole, N., Gulhane, M. (2017). Community Wastewater Treatment with Attached Growth Assisted Constructed Wetland Reactor. Proceedings of the International Conference on Science \& Engineering for Sustainable Development (2017), 327-339. doi: http://dx.doi.org/10.21013/jte.ICSESD201731

(C) International Conference on Science \& Engineering for Sustainable Development\& The Institution of Engineers (India).

\section{(cc) BY-NC}

This work is licensed under a Creative Commons Attribution-Non Commercial 4.0 International License subject to proper citation to the publication source of the work.

Disclaimer: The conference papers as published by the Institute of Research Advances (IRA) are the views and opinions of their respective authors and are not the views or opinions of the IRA. The IRA disclaims of any harm or loss caused due to the published content to any party. 


\section{ABSTRACT}

Constructed wetlands are systems of artificial wastewater treatment which consists of shallow ponds or channels that have been planted with aquatic plants. The treatment is based on the natural, biological, physical and chemical treatment of wastewater. The technique is reported to be cost effective as compared to other methods. The constructed wetlands have impermeable clay or synthetic coatings and artificial structures for controlling the direction of flow, liquid retention time and the water level. However, there are certain limitations of constructed wetland system, which need improvement for its wide adoptability. As such the effort was made to assist the constructed wetland system with attached growth system with the aim to design an economical and user friendly waste water treatment option for the small community. The laboratory scale model was fabricated using GI sheet of thickness $0.5 \mathrm{~mm}$. The overall capacity of the model was 275 L. The laboratory scale reactor model consisted of four compartments out of which first three compartments were based on attached growth system and the fourth compartment acted as constructed wetland reactor. All the three compartments were packed with different types of artificial, semi-artificial and natural media. The fourth compartment consisted of media packed from bottom as aerocon stone layers 03 in numbers followed by snail shell, followed by a soil layer of $80 \mathrm{~mm}$ thick which holds the plants in rows. The reactor was operated as continuous flow reactor with varying detention time and change of different type of media packed in the reactor. The performance of Customized Constructed Wetland reactor was observed under various operating conditions for removal of BOD, COD and TS parameters. The paper presents the details regarding the development of the reactor model, operation of the reactor model and results obtained during the course of study. The paper also cover the discussion regarding the improved performance of reactor noted during the study and adoptability of the developed reactor model for community waste treatment.

Keywords: Artificial Media, B.O.D., C.O.D., Customized Constructed Wetlands, Natural Media, Phyto Remediation Process.

\section{Introduction}

About 50 to 80 percent of domestic wastewater is usually grey water, which is less polluted than other types of wastewater. Grey water can be treated and reused rather more easily than domestic wastewater. Simple low-cost treatment technologies are sufficient to treat the grey water. Biological treatment processes are costeffective and environmentally safe alternative to the chemical treatment of wastewater. Biological treatment is an important and integral part of any wastewater treatment plant that treats wastewater emerging from colonies or industries. The objectives of the biological treatment of wastewater are to remove the organic matter and to stabilize the organic matter. Biological treatment systems are natural treatment systems which rely on mixed biological cultures which break down waste organics and remove organic matter from the wastewater. The treatment systems are designed to maintain a large active mass of bacteria within the system. Biological processes are classified as per the requirement of oxygen of primary micro-organisms responsible for waste treatment. Both aerobic and anaerobic wastewater treatment systems are adopted worldwide to treat the waste water. The treatment systems can be seen as complementary to each other, since in some situations anaerobic systems cannot fulfill the requirements of effluent quality. Aerobic treatment systems have relatively high net sludge yield and requires larger area. The aerobic treatment process requires oxygen where air is injected and circulated inside the treatment tank. This requires additional operation cost for operation. For this reason, aerobic systems cost more to operate and need more routine maintenance than the other systems of treatment. The properly operated and maintained, aerobic systems can provide a high quality wastewater treatment alternative to other systems of treatment. The anaerobic treatment systems produce 
relatively low net sludge than that of the aerobic treatment processes. These treatment systems are small and compact in size. However, anaerobic treatments alone are usually insufficient to meet the effluent discharge standards.

To treat the waste economically, efforts must be directed to treat the waste at generation source itself instead of transporting it to a large distance for treatment at CETP. The waste emerging from cluster of apartments, colonies, Institutions and small townships might be treated at source by selecting the area centrally available such as the open spaces of layout, garden spaces of the layout or other available spaces which are not permissible for construction and development activities. The wastewater treatment options available for treatment might be chosen depending on provision of hygienic environment at reasonably low cost. The treatment to be adopted for wastewater treatment should be simple in operation, easy for maintenance and economical for installation. Limited treatment options are available which emphasizes on economy and simplicity. From last 30 decades various aerobic, anaerobic and facultative treatment are used to treat the wastewater so it is always necessary to use the most efficient and economical method. The most economical and efficient method can be determined by evaluating various design parameters such as initial cost, operation and maintenance cost, $\mathrm{pH}$, detention time, organic loading, hydraulic loading, influent and effluent BOD and COD and many others.

Phyto remediation techniques for the treatment of different types of wastewater have been used by several researchers. These techniques were reported to be cost effective as compared to other methods. Phyto remediation or bioremediation system consists of treatment processes such as constructed wetlands or tidal wetlands which are further classified on the basis of flow regime. Wetlands are generally distinguished based on their water level and on the types of plants, planted within the treatment system. Natural wetlands are effective sinks for metals. Processes of metal removal and mobilization include sedimentation, adsorption, uptake by plants, and microbial reactions including oxidation and reduction. Recently, wetlands for wastewater purification have been constructed for treatment of sewage and urban runoff and also show good potential for concentrating metals from industrial wastewaters and mine seepage.

\section{Combined Attached Growth and Phyto Remediation Process}

Constructed wetlands are systems of artificial wastewater treatment consisting of shallow ponds or channels that have been planted with aquatic plants, which are based on the natural microbial, biological, physical and chemical treatment of wastewater. Typically constructed wetlands have impermeable clay or synthetic coatings and artificial structures for controlling the direction of flow, liquid retention time and the water level.

Considering this prime requirement, to treat the wastewater originating from community with minimum cost at the generation source itself, the present study was undertaken with the objective, to evaluate the performance of Constructed Wetland reactor model for treatment of community waste water. Various modifications were thought to be incorporated in the present treatment system for improved performance. During the analysis of various treatment systems, it was noticed that combination of attached growth system and phyto remediation with certain modification might add certain advantages as well as might reduce the operating cost. The effort was made to assist the constructed wetland system with attached growth system with the aim to design an economical and user friendly waste water treatment option for the small community. The increase in efficiency of the Constructed Wetland reactor by adoption of attached growth assisted constructed wetland reactor was also evaluated. The efforts were principally directed to design the reactors which would be compact in size and treat the waste to a level such that effluent can be utilized for gardening purpose. The compact and aesthetic design of the reactor would permit its placement at one corner of the public garden. The efforts were also made to evaluate the cost economics of various treatment units designed during the study and validate the results obtained during the course of study. The performance of experimental model was analyzed for percent removal of BOD, COD and TS concentrations. 
Initially before the start of study the developed model was fed with seed waste water obtained from a treatment unit located in municipal corporation area and operated for a period of 6 weeks to develop the bacteria on to the media. At the start of the study the models were operated under set operating conditions for a period of 2 weeks to acclimatize the bacteria with the set operating conditions. The details of laboratory scale reactor models developed and various trials performed to carry out the study are listed as below.

\section{Laboratory Scale Customized Constructed Wetland Reactor}

It was proposed to provide the treatment of domestic wastewater by using the experimental laboratory scale model based on combination of treatment such as attached growth system and constructed wetland system. The laboratory scale model of size $1.65 \mathrm{~m} \mathrm{x} 0.5 \mathrm{~m} \times 0.5 \mathrm{~m}$ having inlet and outlet arrangement was fabricated using GI sheet of thickness $0.5 \mathrm{~mm}$. The overall capacity of the model was $275 \mathrm{~L}$. The inlet and outlet arrangement were provided at both ends. The laboratory scale reactor model consisted of four compartments out of which first three compartments were of size $0.2 \mathrm{~m}$ x $0.5 \mathrm{~m} \mathrm{x} 0.5 \mathrm{~m}$ each. The first three compartments were sub divided into two equal compartments with the help of one stationary baffle wall which was placed $50 \mathrm{~mm}$ above the inlet level so as to divide each individual compartment into two compartments having independent compartment volume of $50 \mathrm{~L}$. The fourth compartment was of size 0.4 $\mathrm{m} \times 0.5 \mathrm{~m} \times 0.5 \mathrm{~m}$ and acted as constructed wetland reactor. All the three compartments were packed with different types of artificial, semi-artificial and natural media. The fourth compartment consisted of media packed from bottom as aerocon stone layers 03 in number, $80 \mathrm{~mm}$ thick, having media size ranging from $25 \mathrm{~mm}$ to $45 \mathrm{~mm}$., followed by snail shell layers 03 in numbers and $60 \mathrm{~mm}$ thick. Over this layer crushed aerocon stone layer $60 \mathrm{~mm}$ thick was laid, followed by a soil layer of $80 \mathrm{~mm}$ thick which hold the plants in rows. The reactor was operated as continuous flow reactor with varying detention time and change of different type of media packed in the reactor. The performance of Customized Constructed Wetland reactor was observed under various operating conditions for removal of BOD, COD and TS parameters. The experimental setup of model ispresented as below in Fig. 1.

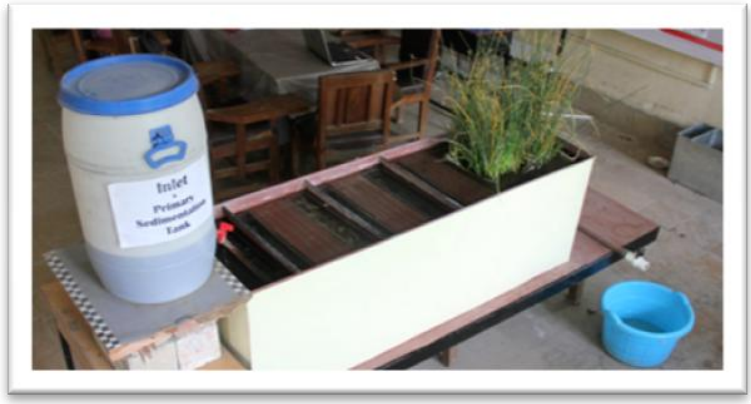

Fig. 1: Laboratory scale Customized Constructed Wetland Reactor

The performance of the laboratory reactor model of Customized Constructed Wetland reactor was analyzed for various iterations performed during the study to suggest, the best suited option to treat the waste at the generation source. Various iterations performed during the study are presented in Table number 1. 
Table 1 Various iterations performed during the study for Customized Constructed Wetland Reactor.

\begin{tabular}{|c|c|c|c|}
\hline $\begin{array}{l}\text { Category of } \\
\text { Reactor }\end{array}$ & Reactor Name & $\begin{array}{l}\text { Option/ } \\
\text { Iteration }\end{array}$ & Iteration \\
\hline \multirow{4}{*}{$\begin{array}{l}\text { Combined } \\
\text { Attached Growth } \\
\text { and Phyto- } \\
\text { Remediat- ion }\end{array}$} & \multirow{4}{*}{$\begin{array}{l}\text { Customized } \\
\text { Constructed } \\
\text { Wetland Rector }\end{array}$} & - & $\begin{array}{l}\text { Customized Constructed Wet-land Reactor } \\
\text { packed with only artificial media }\end{array}$ \\
\hline & & II & $\begin{array}{l}\text { Customized Constructed Wet-land Reactor } \\
\text { packed with artificial media in first two } \\
\text { compartments and semi artificial -natural media } \\
\text { in one compartment }\end{array}$ \\
\hline & & III & $\begin{array}{l}\text { Customized Constructed Wet-land Reactor } \\
\text { packed with artificial media in first } \\
\text { compartment, natural media in second } \\
\text { compartment and semi artificial - natural media } \\
\text { in third compartment }\end{array}$ \\
\hline & & IV & $\begin{array}{l}\text { Customized Constructed Wet-land Reactor } \\
\text { packed with natural media in first two } \\
\text { compartments and semi artificial-natural media } \\
\text { in third compartment }\end{array}$ \\
\hline
\end{tabular}

\section{Media used in Customized Constructed Wetland Reactor}

In the study different types of filter media were used to judge the better performing option to be adopted for customized constructed wetlands. The media studied during the study were Aerocon Stones with the size ranging from $16 \mathrm{~mm}$ to $25 \mathrm{~mm}$, Natural Media such as coconut shell chips, Snail shells and SemiArtificial Media such as Para-wood Charcoal. All the chosen media were having rough surface and porous nature which provided excellent surface for the growth of bacteria. The media packed in the reactor model is presented in Fig. 1.2.

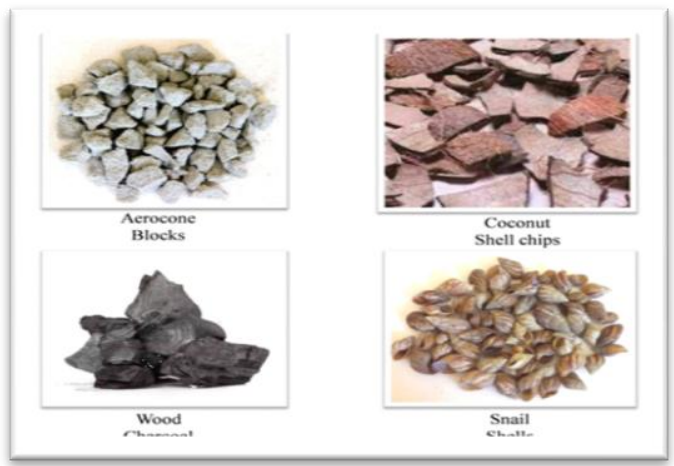

Fig. 2: Media Packed in Customized Constructed Wetland Reactor

2. Working of model and operational parameters

Initially before the start of study, the developed reactor model was fed with seed waste water sludge obtained from a treatment unit located in municipal corporation area and operated for a period of 6 weeks to develop the bacteria on to the media. At the start of the specific study the model was operated under set operating conditions for a period of 2 weeks to acclimatize the bacteria with the set operating conditions. The synthetic wastewater was fed to the inlet tank cum pre sedimentation tank. The wastewater from inlet 
tank was admitted to the inlet chamber from where it was admitted sequentially to the first compartment, second compartment, third compartment and last compartment and finally collected through the outlet provided to the collecting chamber. The wastewater from the inlet chamber entered the first compartment and allowed to flow from the first compartment to the third compartment with down flow-up flow-down flow regime. The wastewater was partially treated in these compartments with attached growth system and was further admitted to fourth compartment which maintains down flow regime. The wastewater released from the compartment No. 3 entered the last compartment from top. The final treatment of wastewater was carried out in constructed wetland reactor. As the wetland grass/plants come in a contact with the wastewater, the nutrients and solids present in wastewater got removed. This treated effluent water was discharged in the collection tank through the outlet provided. The model was operated at the varying detention time of 12 hours, 15 hours, 18 hours, 21 hours, 24 hours, 27 hours and 30 hours. Various wastewater parameters like BOD, COD and TS with respect to influent and effluent were analyzed in different trials. Various trial iterations were carried out to judge the better performing combination for the reactor model under study.

\section{Customized Constructed Wetland Reactor Packed with only Artificial Media (Iteration I)}

During this Iteration, first, second and third compartments from bottom to top were packed with only artificial media such as Aerocon blocks with the size ranging from $16 \mathrm{~mm}$ to $25 \mathrm{~mm}$. The fourth compartment consisted of media packed from bottom with Aerocon stone layers 03 in number, each 80 $\mathrm{mm}$ thick, having media size ranging from $25 \mathrm{~mm}$ to $45 \mathrm{~mm}$, followed by snail shell layers 03 in numbers and $60 \mathrm{~mm}$ thick. Over this layer crushed Aerocon stone layer $60 \mathrm{~mm}$ thick was laid, followed by a soil layer of $80 \mathrm{~mm}$ thick which hold the plants in rows. During the study, the reactor was fed with synthetic waste water having influent BOD $260 \mathrm{mg} / \mathrm{l}$, COD $310 \mathrm{mg} / \mathrm{l}$ and T.S. $340 \mathrm{mg} / \mathrm{l}$. The performance of the reactor model under iteration I for set optimum detention time with respect to BOD, COD and TS removal was noted down for further comparison. Schematic and photographic representation of customized constructed wetland reactor packed with only artificial media during first iteration is presented in Fig. 1.3 and 1.4

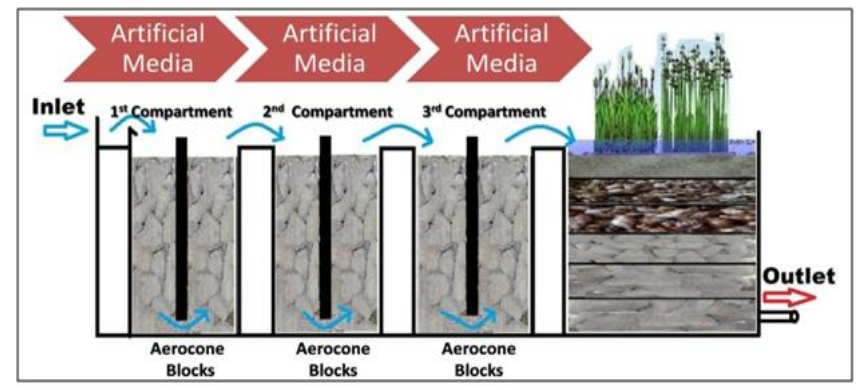

Fig. 3: Schematic Representation of Customized Constructed Wetland Reactor packed with only Artificial Media ( Iteration I ) 


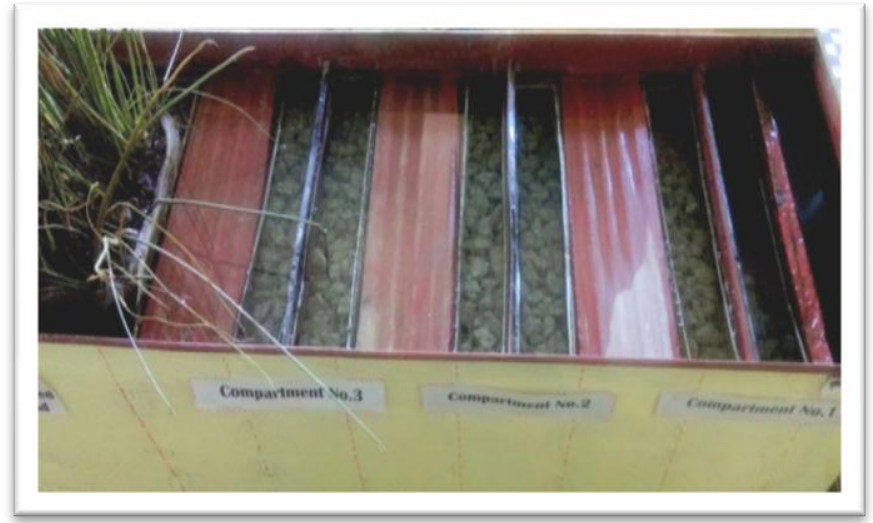

Fig. 4: Laboratory Scale Customized Constructed Wetland Reactor packed with only Artificial Media (Iteration I)

4 Customized Constructed Wetland Reactor Packed With Artificial Media In First Two Compartments and Semi Artificial - Natural Media In Third compartment (Iteration II )

During this Iteration the first and second compartment of size $0.2 \mathrm{~m}$ x $0.5 \mathrm{~m}$ x $0.5 \mathrm{~m}$ having independent compartment volume $50 \mathrm{~L}$ was completely packed with artificial media such as Aerocon Blocks with the size ranging from $16 \mathrm{~mm}$ to $25 \mathrm{~mm}$. The third compartment of size $0.2 \mathrm{~m}$ x $0.5 \mathrm{~m}$ x 0.5 was completely packed with Semi-Artificial-Natural Media such as para-wood charcoal. The media configuration in fourth Compartment was kept same, as it was in the first iteration. The performance of the reactor model under iteration II for set optimum detention time with respect to BOD, COD and TS removal was noted down for further comparison. The schematic and photographic representation of Customized Constructed Wetland Reactor packed with artificial media in first two compartments and semi artificial - natural media in third compartment is presented in Fig. 1.5 and Fig. 1.6.

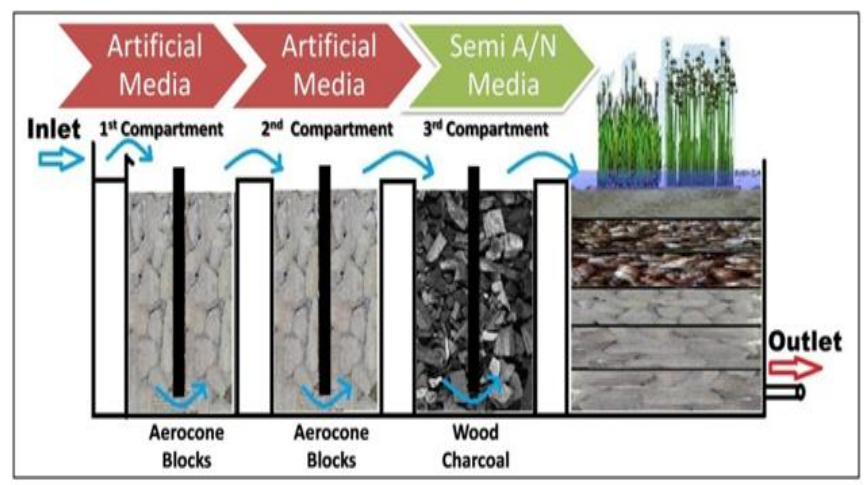

Fig. 5: Schematic Representation of Customized Constructed Wetland Reactor Packed With Artificial Media in First Two Compartments and Semi Artificial - Natural Media in Third Compartment (IterationII) 


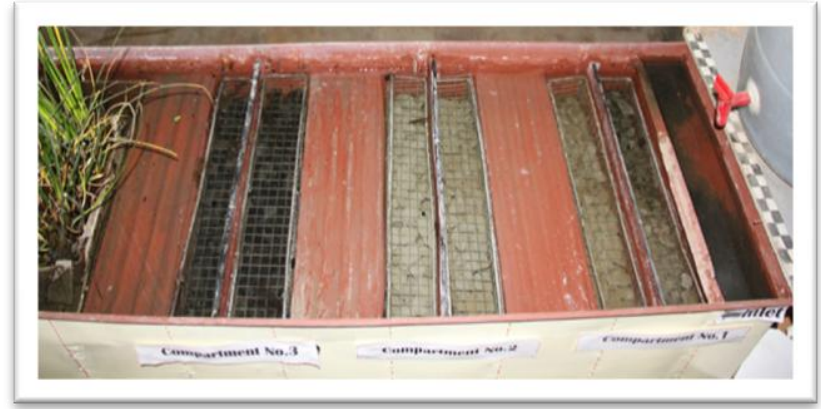

Fig. 6: Laboratory Scale Customized Constructed Wetland Reactor Packed with Artificial Media in First Two Compartments and Semi Artificial - Natural Media in Third Compartment (Iteration II)

5 Customized Constructed Wetland Reactor Packed With Artificial Media In First Compartment, Natural Media In Second Compartment and Semi Artificial- Natural Media In Third Compartment (Iteration III)

During this Iteration the first, second and third compartment of size $0.2 \mathrm{~m} \mathrm{x} 0.5 \mathrm{~m} \mathrm{x} 0.5 \mathrm{~m}$ having independent compartment volume $50 \mathrm{~L}$ were completely packed with Artificial media such as Aerocon Blocks with the size ranging from $16 \mathrm{~mm}$ to $25 \mathrm{~mm}$, Natural Media such as Snail shells and SemiArtificial Media such as Para-wood Charcoal respectively. The fourth Compartment media configuration was kept same, as it was in the first Iteration and second iteration. During the study, the reactor was fed with synthetic waste water having influent BOD $260 \mathrm{mg} / \mathrm{l}$, COD $310 \mathrm{mg} / \mathrm{l}$ and T.S. $340 \mathrm{mg} / \mathrm{l}$. The performance of the reactor model under iteration III for set optimum detention time with respect to BOD, COD and TS removal was noted down for further comparison. The schematic and photographic representation of Customized Constructed Wetland Reactor packed with artificial media in first compartment, natural media in second compartment and semi artificial - natural media in third compartment is presented in Fig. 7 and Fig. 8.

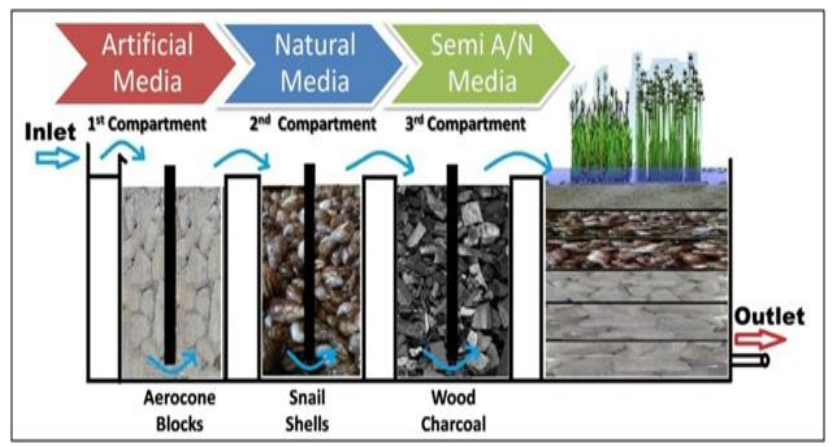

Fig. 7: Schematic Representation of Customized Constructed Wetland Reactor Packed With Artificial Media in First Compartment, Natural Media in Second Compartment and Semi Artificial-Natural Media in Third Compartment (Iteration III) 


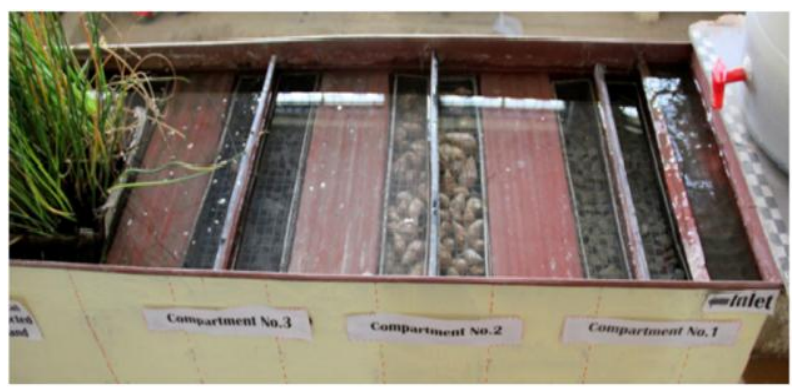

Fig. 8: Laboratory Scale Customized Constructed Wetland Reactor Packed With Artificial Media in First Compartment, Natural Media in Second Compartment and Semi Artificial - Natural Media in Third Compartment. (Iteration III)

6 Customized Constructed Wetland Reactor Packed with Natural Media In first two Compartments and Semi Artificial - Natural Media In Third Compartment (Iteration IV )

The first, second and third compartment of size $0.2 \mathrm{~m}$ x $0.5 \mathrm{~m} \mathrm{x} 0.5 \mathrm{~m}$ having volume 50L was completely packed with Natural media such as Coconut shell chips with the size ranging from $16 \mathrm{~mm}$ to $25 \mathrm{~mm}$, Natural Media such as Snail shells and Semi- Artificial Media such as Para-wood Charcoal respectively. The fourth Compartment media configuration was kept same, as it was in the first, second and third iteration. During the study, the reactor was fed with synthetic waste water having influent BOD $260 \mathrm{mg} / \mathrm{l}$, COD $310 \mathrm{mg} / \mathrm{l}$ and T.S. $340 \mathrm{mg} / \mathrm{l}$. The performance of the reactor model under iteration IV for set optimum detention time with respect to BOD, COD and TS removal was noted down for further comparison. The schematic and photographic representation of Customized Constructed Wetland Reactor packed with natural media in first two compartments and semi artificial - natural media in third compartment is presented in fig. 1.9 and fig. 1.10.

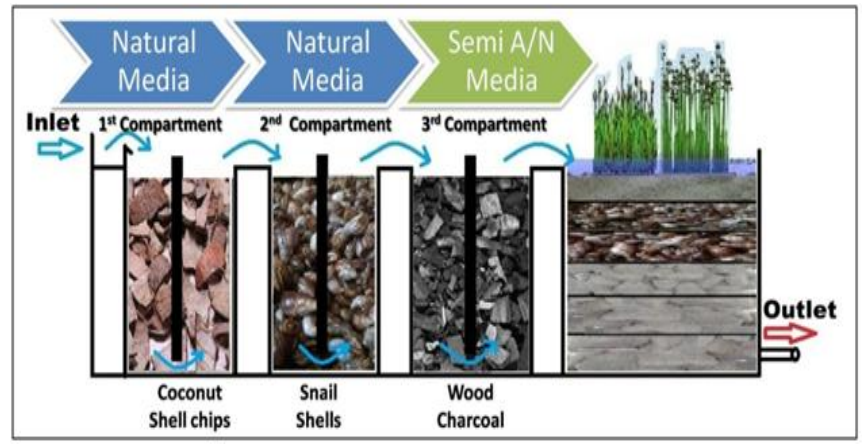

Fig. 9:Schematic Representation of Customized Constructed Wetland Reactor Packed with Natural Media In First Two Compartments and Semi Artificial - Natural Media In Third Compartment. (Iteration IV) 


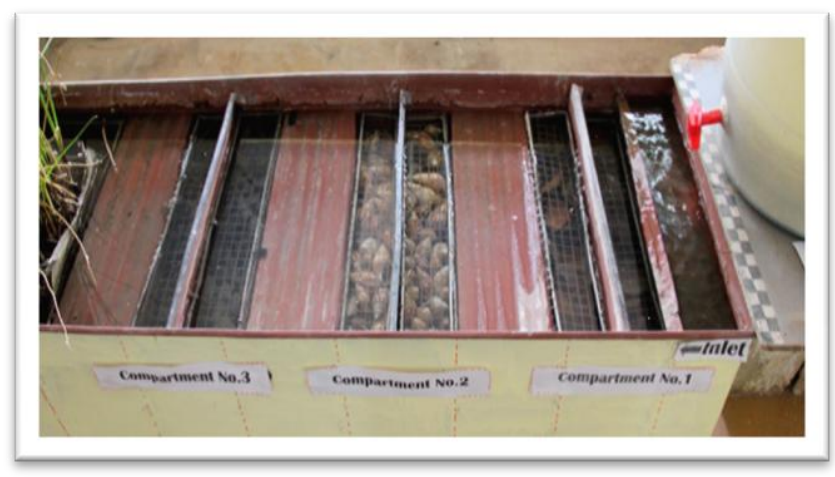

Fig. 10:Laboratory Scale Customized Constructed Wetland Reactor Packed with Natural Media in First Two Compartments and Semi Artificial - Natural Media In Third Compartment (Iteration IV)

\section{Results}

The performance of reactor model under various trials was analyzed and the results obtained are presented in sections 4.1 to 4.4

4.1: Analysis of Performance of Laboratory scale model of Customized Constructed Wetland Reactor Packed with only Artificial Media (Iteration I )

The performance of the reactor model was analyzed for optimization of Detention time in First Trial. The reactor model was operated at varying detention time ranging from 12 to 30 hours at an interval of 3 hours. The performance of the Customized Constructed Wetland Reactor was noted at varying detention time. It was observed that there was continuous increase in percent removal efficiency with the increase in detention time from 12 hours to 30 hours. The detention time of 24 hours exhibited better performance in terms of BOD, COD and TS removal. It was also observed that the negligible increment on removal efficiency for BOD, COD and TS was decreasing after 24 hours of detention time and as such detention time of 24 hours was adopted for the study. The critical analysis of the observations noted for the performance brings forward the fact that the maximum removal efficiency of $75.65 \%, 74.25 \%$ and $76.08 \%$ for BOD, COD and TS respectively was observed. The results obtained during the iteration are presented graphically in Fig. 1.11 and Fig. 12

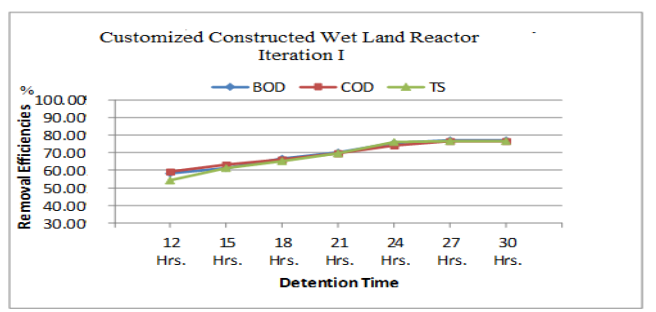

Fig. 11: Performance of Customized Constructed Wetland Reactor Packed with only Artificial Media in all three compartments at varying detention time. 


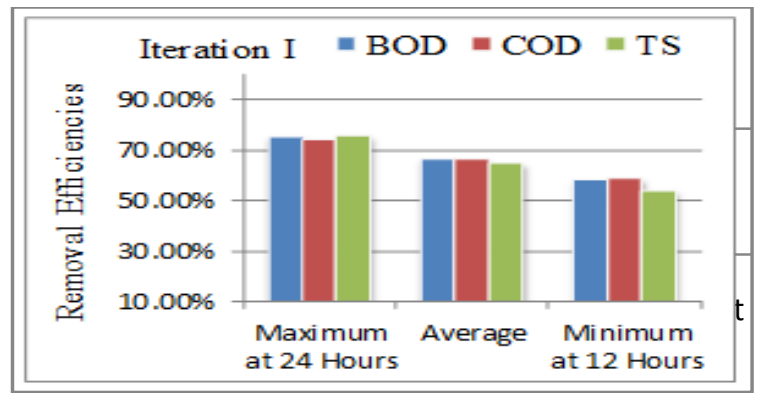

Fig. 12: Graphical Representation of Performance of Customized Constructed Wetland Reactor Packed with only Artificial Media in all three compartments at varying detention time (Iteration I)

4.2: Analysis of Performance of Laboratory scale model of Customized Constructed Wetland Reactor Packed with Artificial Media in first two compartments and Semi Artificial - Natural Media in Third Compartment. (Iteration II )

The performance of the reactor model was observed for set optimum operating condition and the results obtained related with \% removal efficiency in terms of BOD, COD and TS were critically analyzed to judge the efficiency of the reactor model. The critical analysis bring forward the fact that the maximum removal efficiency of $80.77 \%, 81.29 \%$, and $84.70 \%$ for BOD, COD and TS respectively. The average efficiency for this trial was noted to be $79.38 \%, 80.08 \%$ and $82.82 \%$ for BOD, COD and TS respectively. The results obtained during the iteration are presented graphically in Fig.13.

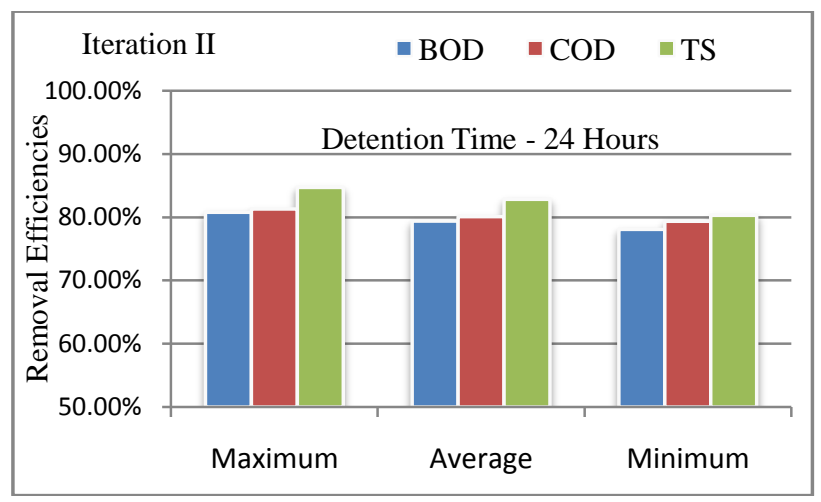

Fig.13: Graphical Representation of Performance of Customized Constructed Wetland Reactor packed with Artificial Media in first two compartments and Semi artificial - Natural media in third compartment at 24 hours detention time.(Iteration II)

4.3: Analysis of Performance of Laboratory scale model of Customized Constructed Wetland Reactor packed with artificial media in First compartment, Natural Media in Second compartment and Semi Artificial - Natural Media in Third compartment.

(Iteration III)

The performance of the reactor model was observed for set operating conditions and the results obtained related with \% removal efficiency in terms of BOD, COD and TS were critically analyzed to judge the efficiency of the reactor model. The critical analysis claims the maximum removal efficiency of $83.84 \%$, $85.48 \%$, and $85.58 \%$ for BOD, COD and TS respectively. The average efficiency for this trial was noted to be $82.30 \%, 84.09 \%$ and $84.17 \%$ for BOD, COD and TS respectively. The results obtained during the iteration are presented graphically in Fig. 14. 


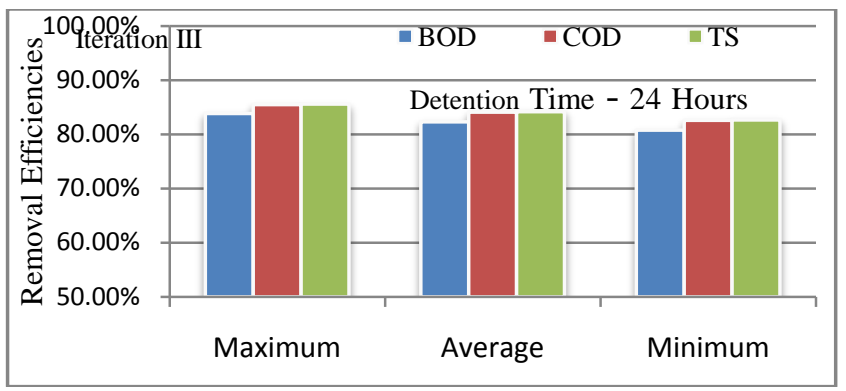

Fig. 14: Graphical Representation of Performance of Customized Constructed Wetland Reactor packed with Artificial Media in first compartment, Natural media in second compartment and Semi artificial -

Natural media in third compartment at 24 hours detention time (Iteration III)

4.4: Analysis of Performance of Laboratory scale model of Customized Constructed Wetland Reactor Packed with Natural Media in First two compartments and Semi Artificial - Natural Media in Third Compartment ( Iteration IV )

The performance of the reactor model was observed for set optimum operating conditions and the results obtained related with \% removal efficiency in terms of BOD, COD and TS were critically analyzed to judge the efficiency of the reactor model. The critical analysis claims the maximum removal efficiency of $78.46 \%, 80.32 \%$, and $80.29 \%$ for BOD, COD and TS respectively. The average efficiency for this trial was noted to be $76.46 \%, 78.55 \%$ and $78.43 \%$ for BOD, COD and TS respectively. The results obtained during the iteration are presented graphically in Fig. 1.15.

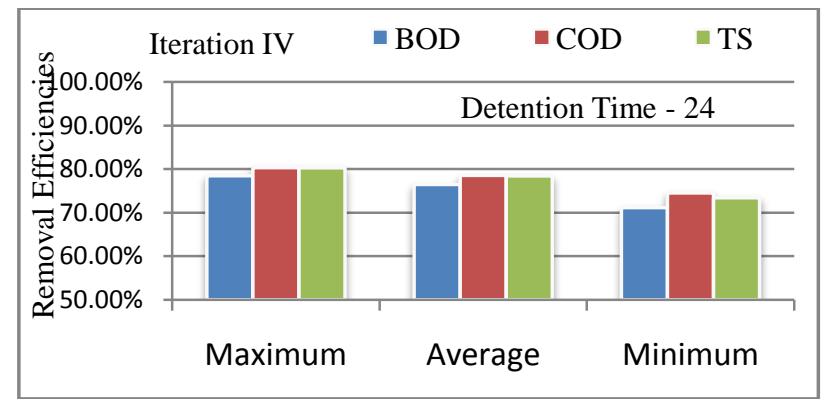

Fig.15: Graphical Representation of Performance of Customized Constructed Wetland Reactor packed with Natural media in first two compartments and Semi artificial - Natural media in third compartment at 24 hours detention time (Iteration IV)

\section{Conclusion}

The critical review of the performance of the reactor model under study claims that customized constructed wetland reactor may be the choice of treatment for treatment of waste emerging from colonies, cluster of apartments and small townships.

The laboratory reactor model namely Customized Constructed Wetland based on combine attached growth system and phyto remediation system operated at detention time of 24 hours recorded maximum percentage removal efficiencies of $82.30 \%, 84.09 \%$ and $84.17 \%$ for BOD, COD and TS respectively when the Laboratory scale model of Customized Constructed Wetland Reactor was packed with artificial 
media in first compartment, Natural Media in second compartment and Semi Artificial - Natural Media in third compartment.

The initial installation cost including civil cost, media cost, operator cost and maintenance cost for the reactor model namely Customized Constructed Wetland Reactor is moderate. However the reactor unit doesn't require machinery cost and as such the operating cost is almost minimum. The efficiency in terms of removal of BOD and COD is moderate and therefore Modified Customized Constructed Wetland Reactor may prove to be the better choice when recurring cost is a primary thought. Also the reaction rate ' $\mathrm{k}$ 'calculated by MATLAB Optimization Toolbox for Customized Constructed Wetland Reactor is moderate. The reactor unit may be installed at one corner of the layout garden or open unutilized place within the layout or near to open natural drain. The reactor unit stationed within remote corner of the garden will add to the greenery of the garden and may prove to be one of the nice choices for the treatment of community waste.

\section{References}

[1] Atif Mustafa, (2013) ; "Constructed Wetland for Wastewater Treatment and Reuse: A Case Study of Developing Country", International Journal of Environmental Science and Development, Vol.4, No.1 pp. 31-42

[2] Metcalf and Eddy, Inc., (2003) ; "Wastewater Engineering: Treatment and Reuse," Fourth Edition, Tata McGraw Hill Publishing Company Limited, New Delhi,

[3] Mustafa A., (2009) ; "Nutrient Removal with Integrated Constructed Wetlands", Thesis of University oEdinburgh, pp. 5-17.

[4] Sawyer Clair N., Mc. Carty Perry L. and Parkin Gene F.; (2003) "Chemistry for Environmental Engineering and science", Fifth Edition, Tata McGraw Hill Publishing Company Limited, New Delhi, pp 631-648

[5] Suntud S., (2007) ;“Application of Para-Wood Charcoal As the Media of The Vertical-flow Constructed Wetland for Treatment of Domestic Wastewater", African Journal of Agricultural Research, Vol.2(4),pp. 191-199.

[6] Tayade S. T., (2005) ; "Feasibility of Constructed Wetland for Treatment of Sewage National Environmental Engineering Research Journal, Vol. 2, Issue 4, pp. 65-78.

1. A book, "Egg. Properties of soils, Tata McGraw Hill, New Delhi, 1978. By Gulhati S.K.

2. A book "Transportation Engineering". By N.L Arora. 